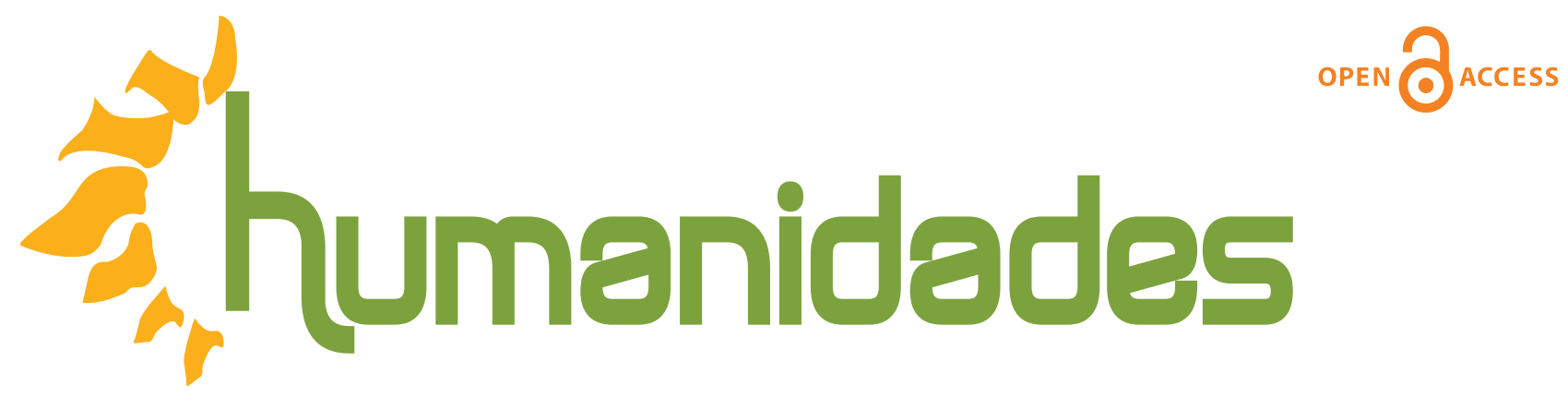

Revista de la Escuela de Estudios Generales, Universidad de Costa Rica

Julio-diciembre, 2019 •Volumen 9, número 2 • EISSN 2215-3934 • pp. 1-17

Recibido: 01-Febrero-2019 Aceptado: 06-Mayo-2019

\title{
Heidegger, Schapiro, Derrida: lo que se hace presencia en los zapatos. Una polémica extendida a la obra de María Teresa Hincapié Una cosa es una cosa
}

DOI: https://doi.org/10.15517/h.v9i2.37656

\section{Fabrizio Pineda Repizo}

Máster en Filosofía, Máster en Estudios Culturales, Candidato a Doctor en Arte y Arquitectura Universidad Autónoma de Colombia, Colombia

Correo electrónico: adryan.pineda@fuac.edu.co

Este texto nace de unas ideas presentadas al concurso "Reconocimiento Nacional a la Crítica y el Ensayo: Arte en Colombia” en la categoría de Texto Corto (menos de 10.000 caracteres incluyendo espacios). El texto que aquí se presenta realiza un considerable desarrollo teórico y reflexivo.

Todos los derechos reservados. Universidad de Costa Rica. Esta revista se encuentra licencida con Creative Commons. Reconocimiento-NoComercial-SinObraDerivada 3.0 Costa Rica. Correo electrónico: humanidades@ucr.ac.cr/ Sitioweb: http: //revistas.ucr.ac.cr/index.php/humanidades 


\section{Heidegger, Schapiro, Derrida: lo que se hace presencia en los zapatos. Una polémica extendida a la obra de María Teresa Hincapié Una cosa es una cosa}

\section{Resumen}

Este artículo pone en diálogo una reflexión en torno a la obra Una cosa es una cosa de la artista performática colombiana María Teresa Hincapié y el entrecruzamiento conceptual en torno al concepto de cosa, sujeto y verdad que tiene lugar entre Martin Heidegger, Meyer Schapiro y Jacques Derrida. Siguiendo la lectura de la polémica entre los dos primeros pensadores que haría el filósofo francés, se busca destacar la relevancia de evitar interpretar la presencia de un objeto de uso, como unos zapatos, en una obra de arte como una remisión a o representación de un sujeto, y en su lugar resaltar la manera en que su propia presencia, como ilustra la obra de Hincapié, consiste en una invitación a unos juegos de sentido que mantienen abierta la expresión de la materialidad constitutiva de lo que somos.

\section{Heidegger, Schapiro, Derrida: What Becomes Presence in Shoes. A Controversy Extended to the Work of María Teresa Hincapié Una cosa es una cosa}

\footnotetext{
Abstract

This paper puts into dialogue a reflection on the work Una cosa es una cosa by the Colombian performance artist María Teresa Hincapié and the conceptual intercrossing around the concept of thing, subject and truth that takes place between Martin Heidegger, Meyer Schapiro and Jacques Derrida. Following the reading of the controversy between the first two thinkers that would make the French philosopher, it seeks to highlight the relevance of avoiding interpreting the presence of an object of use, such as shoes, in a work of art as a reference to or representation of a subject, and instead highlight the way in which his own presence, as Hincapié's work illustrates, consists of an invitation to games of meaning that keep open the expression of the constitutive materiality of what we are.
}

Palabras clave: arte contemporáneo, obra de arte, filosofía, estética
Keywords: contemporary art, works of art, philosophy, aesthetics 
En 1990 María Teresa Hincapié llevó en cajas de cartón y bolsas de papel un extenso conjunto de cosas, tomadas de su propia vivienda, al Pabellón " $F$ " de Corferias en Bogotá, Colombia. Allí, descalza y con ropa cómoda, empezó a extraer una a una cada cosa, a llevarlas a un punto del espacio confinado en el que se encontraba y, no sin cariño y cuidado, a ubicar cada cosa en el suelo, una tras otra, en una fila ordenada que solo se quebraba en un ángulo recto al llegar a la esquina; al final, la fila adopta la forma de una espiral de cuadrados e Hincapié se da a la lenta tarea de empacar nuevamente sus objetos. En 1990 María Teresa Hincapié obtuvo el primer premio del XXXIII Salón Nacional de Artistas con la obra Una cosa es una cosa.

No fue esta la primera vez que la artista colombiana performática ve y hace ver cosas. Pero es probable que esta obra sea en la que más se evidencia su interés por las cosas que pueden decir (y lo que las cosas pueden decir). Es como si reconociera que los objetos que llenan nuestro mundo, que le otorgan su cercanía y que nos brindan su fiabilidad, guardasen una secreta verdad. ¿Cuál es la verdad de las cosas? Que el enunciado "una cosa es una cosa" no agota -en su aparente tautología- lo que Heidegger llamaría el ser-cosa de la cosa. ¿Cuál es la función de este enunciado? ¿Cuál es la función de la cópula? ¿La primera cosa se identifica con la segunda o se trata de una generalización "esta cosa es una cosa"? ¿A quién se dirige el enunciado y con qué fuerza ilocucionaria: es un mandato o es una declaración de principios o de un límite? ¿Quién puede decir "una cosa es una cosa": el que organiza las cosas de la casa, de la rutina, del desorden de la vida? ¿Y qué cosa es la cosa que puede enunciarlo? Finalmente, tras estas preguntas, o debajo de ellas, ¿qué es la cosa y por qué la cosa se hace obra de arte?

Habría una mirada particular, pero común, respecto a la obra de Hincapié: es la artista quien habla y habla de sus cosas, pues son, en efecto, sus cosas. Las cosas son testigos fiables de su propietaria y ella está ahí para validar su testimonio. Es una versión en la que los objetos son crónicas de la vida de su propietaria y, en consecuencia garantes de una verdad, a saber, hay un sujeto para el que son y existen. Aquí se entrelaza una verdad acogida en general a la hora de pensar la relación entre objeto y sujeto: los objetos existen para dar al sujeto un garante material de sí y de su historia. 
Pero probablemente esta no sea la única ni la más adecuada manera de comprender la relación entre estos términos en la obra de Hincapié. Lo que acontece en ella trastoca esta verdad e invita a reescribirla, esto es, diferir de ella y seguir la huella de sus relaciones.

Tómese una cosa; unos zapatos sacados de una bolsa. ¿Los zapatos en la obra son de la artista, le pertenecen, o ya en la obra se visualiza otra relación con las cosas? Alguien podría objetar: "una cosa es una cosa, aquello es otra cosa". Pero la confusión de las palabras se mezcla en la obra con la confusión de las cosas. ¿Cuál? La de la verdad de aquello que se visualiza en la obra: unos zapatos extraídos de todo contexto común en el que pueden ser, de hecho, zapatos.

Empero, Hincapié no es la primera en invitar a reconsiderar esta verdad. El llamado a Heidegger no es gratuito, y su texto El origen de la obra de arte de 1936 ya abordaba esta cuestión a partir del cuadro de Vincent Van Gogh Zapatos, el cual es un óleo sobre lienzo de 1886 que Heidegger vería en Ámsterdam en 1930 según carteo con Meyer Schapiro en fechas posteriores a su escrito. Para Heidegger lo propio de la obra de arte es el desocultamiento de la verdad que acontece en ella. La verdad acontece en virtud de su esencia y esta, a su vez, se muestra por aquello que se da primeramente a la experiencia, esto es, su carácter de cosa. El carácter de cosa de la obra de arte es el que nos revela lo que la obra es como símbolo o alegoría, lo añadido a la cosa (Heidegger, 2012, p. 13). Cada vez que nos topamos con la cosa en la obra, se abre la posibilidad de un acontecer de la verdad. Por ello, en palabras de Javier Domínguez, "la verdad del ser como desocultamiento de lo existente no es nunca un estado definitivamente logrado, sino un acontecimiento que tiene que ser renovadamente provocado” (Domínguez, 1991, p. 202).

Pero, ¿cómo se evidencia el carácter de cosa de la obra que da apertura a la verdad? ¿Y sobre qué cosa? Hay aquí dos facetas y dos cosas: por un lado, la obra misma es una cosa con un algo añadido que no elimina su ser cosa; pero, además, lo que desoculta es, también, una cosa, aquello que arroja y sobre lo que da luz. Es por ello que el cuadro Zapatos de Van Gogh es, per se, una cosa y el par-de-zapatos en la obra (que guarda una verdad en obra) es también una cosa. 
Diríase que es por lo que tiene de obra Zapatos que se erige la verdad en torno a la cosa par-de-zapatos, pero también es cierto que el ser cosa de Zapatos, al igual que del par-de-zapatos, es necesario para provocar la verdad en la obra. A partir de ello, Heidegger exclama que la cosa en la obra es, en efecto, un par-de-zapatos y, más aún, un par-de-zapatos-de-campesino (genérico de la cosa) calzados por una campesina labradora que los usa para salir al campo de trigo a trabajar. El mundo que se abre aquí remite a la vida de la labradora y a la tierra que han de pisar, en una relación dialéctica con la campesina, los zapatos en obra.

Sin embargo, Meyer Schapiro (1968), tras correspondencia con Heidegger, pone en cuestión esta verdad: para Schapiro, dado que en 1886 Van Gogh se encontraba en Paris, como lo atestiguan los escritos de su amistad con Gauguin, dichos zapatos no podían ser los de una campesina; antes bien, Van Gogh guardaba en su residencia unos zapatos de su época de ministro que pudieron ser el motivo del cuadro. De ahí que para Schapiro, nada en el cuadro de Van Gogh exprese el ser de los zapatos-de-la-campesina y su mundo de trabajo en el campo, sino que son "los zapatos del artista, por ese entonces un hombre del pueblo y la ciudad" (Schapiro, 1994, p. 138). Si confiamos en el análisis de fuentes de Schapiro, los zapatos son un retrato del propio artista y la verdad encontrada por Heidegger no es más que una proyección imaginaria del filósofo.

¿Qué sucede entonces con el desocultamiento de la verdad de lo existente? ¿La cosa ha perdido su secreto original y se ha develado otra cosa en el rigor del científico? Heidegger (2002) está convencido de su verdad: "ha sido la obra de arte la que nos ha hecho saber lo que es de verdad un zapato" (p. 25). Pero parece que ese zapato tenía otro dueño y otro mundo al que según Heidegger pertenecía y ha producido una apertura de lo ente en otra tierra, la ciudad.

Ahora bien, introduzcamos en esta polémica otros zapatos, los que María Teresa Hincapié saca de sus cajas en uno de sus tantos desplazamientos. ¿Qué podría interpretarse aquí? Claramente ya no estamos frente a una imagen de zapatos, unos tacones-de-mujer, ni cabe dudar su procedencia, pues la artista dice públicamente "son mis zapatos". 
Siguiendo a Schapiro, la verdad estaría establecida incluso antes de poder dejarse interpelar por la obra. Pero ya en la obra, ¿estos zapatos son de Hincapié? ¿El mundo que abren son solo los de la referencia autobiográfica de la artista? Heidegger (2012) ofrece un camino diferente al de Schapiro: "el camino hacia la determinación de la realidad de cosa que tiene la obra no conducirá de la cosa a la obra, sino de la obra a la cosa" (p. 28). Debería decirse que Schapiro, en su aproximación metódica a la obra, ha recorrido el camino de la cosa a la obra, tal como asignaríamos los tacones a Hincapié; pero la invitación de Heidegger es más espinosa: la cosa en la obra ya no es un utensilio, sino que lo que la obra tiene de obra invita a pensar un algo añadido a la cosa. Decir que ya no es un utensilio implica aceptar que ya no está ligado al mundo del sujeto al que remiten, esto es, los portadores de los zapatos (de campesino, los tacones).

En el último capítulo de su texto La verdad en pintura, Jacques Derrida se mete en la discusión y abre más la extrañeza de la verdad en esta correspondencia al cuestionar, así en Heidegger como en Schapiro, el impulso de restitución de los zapatos a su dueño original:

Todos los grandes profesores habrán invertido mucho, como se dice, en estos zapatos, fuera de uso por más de una razón. Se los han vuelto a poner. [...] Tentación, inscripta entonces en el objeto mismo, de (re)poner(se)lo: ponerse los zapatos en sus pies, (re)poner(se)lo al sujeto, al auténtico portador o propietario restablecido en sus derechos y reinstituido en su estar-de-pie. La estructura de la cosa o del proceso obliga entonces, y siempre, a agregar. La medida es aquí de retorsión suplementaria”. (Derrida, 2005, p. 288)

Una vez los zapatos de campesino o los tacones están en obra, en sí mismos, actuando en la obra, uno y otro de los pensadores se ven abocados a añadirles lo que les falta, unos pies con nombre que los portan y detentan. Pero el caso de los tacones es diferente por su abierta explicitación: si llegaron como los zapatos de la artista, en la obra ya no son utensilios, por ende, ya no son de la artista, son medios de otra acción y acontecer, de un "experimentar con el objeto" (citada por Gómez, 2010, p. 45), según dice la artista. El crítico y curador, José Roca (2010) cae en la trampa de Schapiro al decir que en la obra de Hincapié "la interminable duración de sus acciones pone en evidencia que su destinatario final es en realidad ella misma" (p. 162). 
Pero ¿y si su carácter de cosa expuesto, desnudo en la obra yace precisamente en dejar abierta la suplementariedad? Los zapatos, "desatados de todas maneras, nos conciernen o nos miran, boquiabiertos, es decir mudos, dejándonos hablar, desconcertados frente a aquellos que los hacen hablar [...] y a los que ellos hacen hablar en verdad. Se volverían sensibles, hasta el ataque de risa imperturbablemente retenido, a lo cómico de la cosa" (Derrida, 2005, p. 276).

Al dejarlos reposar "desatados", afirma Derrida, la relación con el sujeto portado queda omitida, y permanecen como soporte anónimo, presencia de un sujeto ausente. Restituir un signatario de la verdad de los zapatos en la obra conlleva cerrar la apertura de la obra en una unidad asible y enunciable. ¿No es esto restituir su utilidad como zapatos para alguien?

Aun así, resulta ineludible considerar que lo que vemos es, de hecho, un utensilio: zapatos, tacones, velas, cepillos. Hincapié lleva sus “pertenencias”, describe Roca, y las ordena en el espacio de exposición. Pero el resultado, en palabras de este curador, consiste en que "las relaciones entre los objetos comienzan a aflorar de manera espontánea en una cadena de asociaciones que se basa más en la experiencia real de las cosas que en sus caracteres formales o funcionales, que son la forma como habitualmente tendemos a categorizarlos" (Roca, 2010, p. 162). Se construye una otra experiencia "real” de las cosas en la obra. Así, se abre aquí un doble ser de las cosas: son utensilios, la obra adopta utensilios y hace ver utensilios, pero, a la vez, son meras cosas proyectadas en la obra. En nuestra cotidianidad, ver el zapato es ver ya sus usos para mí como sujeto y para el mundo en el que habito. Pero este vínculo con el usuario lo distingue tanto de la cosa como de la obra de arte. Pues el utensilio es una cosa con carácter de utilidad, carácter tampoco compartido con la obra, o dejaría de ser obra. Cosa y obra comparten el reposar espontáneamente en sí mismas, utensilio y obra comparten el ser creadas por mano del hombre. 
Cabe recordar que para Heidegger lo ineludible de los utensilios se basa en los modos de determinación de las cosas, a saber:

- La cosa es la suma de sus propiedades, determinación que aleja la cosa de su esencia en tanto solo podemos predicar sus propiedades en la estructura del lenguaje.

- La cosa es una multiplicidad de lo que se da en los sentidos, lo cual supone una extrañeza en el modo de percibir el objeto, pues siempre vemos más que un cúmulo de sensaciones.

- La cosa es una materia con-formada, interpretación que supone que la cosa se dirige a nosotros por su aspecto y cuya materia y forma presupone el uso al que está destinada la cosa. Particularmente esta determinación implica saltar directamente sobre la utilidad del utensilio: "materia y forma habitan, como determinaciones de lo ente, en la esencia del utensilio [...] no son en ningún modo determinaciones originarias de la coseidad de la mera cosa" (Heidegger, 2012, p. 19).

De ahí que al ver los zapatos en el cuadro de Van Gogh y abrir su ser-utensilio, Heidegger pueda decir que se trata de unas botas campesinas que "lleva la labradora cuando trabaja en el campo y solo en ese momento son precisamente lo que son. Lo son tanto más cuanto menos piensa la labradora en sus botas durante su trabajo, cuando ni siquiera las mira ni las siente" (Heidegger, 2012, p. 23). Es por ello que la verdad en la obra no puede consistir en una restitución de los zapatos -o tacones- a su propietario. Este modo de la verdad estaría atado a los tres modos de determinación de la cosa que impiden llegar al ser de la cosa y nos atrapan en el utensilio, "nos cierran el camino hacia el carácter de cosa de la cosa, así como al carácter utensilio del utensilio y sobre todo al carácter de obra de la obra" (Heidegger, 2012, p. 21). La fiabilidad del utensilio yace precisamente en su posibilidad de pasar desapercibido en el ejercicio de su utilidad, en no cuestionar su existencia ni sus posibilidades más allá del uso. Pero los zapatos o los tacones en la obra de arte son inútiles, tanto como la obra misma. Y, empero, están ahí, arrojados, presentes, evidentes como cosas -experiencia contraria a la del útil. Heidegger lo plantea al señalar que, si bien lo útil se ha manifestado a través de la obra, el ser-utensilio pertenece a los zapatos-de-campesino-de-la-labradora, no a los zapatos en la obra. Al decir Derrida (2005): 
En lo inútil [...] la verdad de lo útil aparece. Aparece en la puesta en práctica de la producción inútil. [...] La verdad de la presentación, en su parecer, sobrecarga lo inútil de valor, aumenta su plus-valía al atarlo simbólicamente a su pertenencia. Esta, diferencia capital, ya que se trata de la cabeza del sujeto, no es la de un sujeto propietario, detentor o portador de los zapatos. Ni siquiera es la de tal o cual mundo, por ejemplo el de la campesina que solo es, precisamente, un ejemplo. Se trata, para cualquier producto y cualquier utilidad, de la tierra y del mundo". (p. 360)

Probablemente sea esta una razón por la que Heidegger acude a "mundo" y "tierra" para captar lo que se abre en la obra. Javier Domínguez (1991) expone la relación entre estos conceptos de la siguiente manera:

La obra instaura un mundo, es un abrirse, pero con la misma fuerza es un reservarse a sí misma y un cerrarse. La copertenencia de estos dos momentos del abrirse y el cerrarse es lo que prohíbe afirmar que la obra es sólo un vehículo trasmisor de un significado que ha de ser localizado en otra parte, y sienta más bien de presente que dicha pugna íntima es lo que pone a regir la obra como una especie de dictamen, como algo ineludible e irremplazable, como algo que obliga al contemplador a demorarse en ella. (p. 197)

De esta manera, ese componente "matérico", ineludible a los sentidos, es la tierra sobre la que se erige la obra: la piedra, el tono, el color, la palabra y también el cuero y el caucho. Sobre ella se funda la obra como trabajo del artista. Pero, a la vez, afirma Heidegger (2012), "la obra debe abandonarse a su pura autosubsistencia [...] el artista queda reducido a algo indiferente frente a la obra, casi a un simple puente hacia el surgimiento de la obra que se destruye a sí mismo en la creación” (p. 28). Ese abandono se funda y surge de la tierra para abrir un mundo que se instala en la obra, se erige en ella. Todo lo que vemos - cada tipo de zapato- es tierra, pero no es mundo. "Un mundo no es un objeto que se encuentre frente a nosotros y puede ser contemplado. Un mundo es lo inobjetivo a lo que estamos sometidos mientras las vías del nacimiento y la muerte, la bendición y la maldición nos mantengan arrobados en el ser" (Ibíd, p. 32). El mundo no se reduce a los objetos en obra, sino que los destaca como soporte; y sobre esta tierra "el hombre histórico funda su morada en el mundo" (Ibíd, p. 33). 
La obra es el lugar de encuentro y combate entre tierra y mundo, entre la materialidad ineludible que acoge y la erección de un mundo que expone el ser en su historia y acontecer. "Pero esto no sucede para que la obra reduzca y apague de inmediato la lucha por medio de un insípido acuerdo, sino para que la lucha siga siendo lucha. Al levantar un mundo y traer aquí la tierra, la obra enciende esa lucha" (Ibíd, p. $35)$.

Y sin embargo, Derrida (2005) apuntala esta lectura de Heidegger con una inferencia: el plus que excede la cosa y bordea el utensilio en el ser de la obra requiere ver los zapatos desatados de su "alcance subjetivo [...], de quien supuestamente llena los zapatos" (p. 353). Ello significa que esta apertura es evidenciada no porque sea la verdad en la obra, sino porque se llega a ella a través de la obra, o mejor, a través de reconocer la inutilidad de la obra misma y de lo visto en la obra, esto es, los zapatos en obra. De lo cual se siguen dos conclusiones: por una parte, es un error considerar que la verdad que se abre en el cuadro Zapatos es aquella de zapatos-de-campesina-en-el-campo, es decir, la verdad de un sujeto portador, pues esta solo corresponde al carácter utensilio de los zapatos ajeno a la inutilidad de la obra; en consecuencia, por otra parte, cometeríamos el mismo error de ingenuidad metódica de Schapiro al restituir como portador de zapatos a la artista, al limitar la interpretación a la pertenencia de los tacones a Hincapié. La verdad que acontece en la obra no es la de a quién remiten los zapatos, sino qué queda abierto en la obra -al punto que el (la) artista mismo(a), sobre todo en el performance, sería una cosa más en el ser obra de la obra.

Debe ser, entonces, mucho más que el mundo de la labradora el que se expone en el Van Gogh, y tanto más lo que corresponde a las cosas de Hincapié, pues si para la artista la "la acción es el material por excelencia" (citada por Gómez, 2010, p. 49) del performance, el mundo que corresponde a esta obra no es solo el que reposa en los objetos, sino el que se asienta en la acción. ¿Cuál es entonces el sentido de la verdad como desocultamiento del ente en esta obra? Aún es necesario aclarar este concepto. 
Para Heidegger, el desocultamiento de lo ente es un acontecimiento que no se reduce a la propiedad de las cosas, ni de las proposiciones. La esencia yace en la confrontación entre la verdad y la no-verdad, pero la no-verdad no es falsedad, sino lo que ha estado oculto. En consecuencia, en la obra acontece el desocultamiento de la verdad al extraer el ente de lo que ha estado oculto y exponerlo, hacerlo aparecer. En el caso de la pintura de Van Gogh, se manifiesta el mundo y la tierra que rodean el ser utensilio del zapato. En la obra, dice Heidegger, "se descubre el ser que se encubre a sí mismo" (2012, p. 40). Resulta, por ende, demasiado rápida y estrecha la crítica de Schapiro (1994) al afirmar que "el filósofo se ha engañado a sí mismo" al realizar "un conjunto de asociaciones con lo campesino y la tierra, que no se sostienen en la pintura misma” (p. 138); más aún, afirma este mismo teórico del arte: Heidegger no tuvo en cuenta la presencia del artista, esto es, el hecho de que Van Gogh "aísla sus zapatos roídos como el tema de una pintura" y, con ello, “como una porción de sí mismo” (Ibíd, p. 140).

Pero la obra de Van Gogh interpelaría por un fundamento que se encuentra antes de la constitución del "subjectum”, por lo cual, al decir de Derrida (2005), "plantearle la pregunta del "sujeto", del sujeto de este par de zapatos, sería tal vez comenzar por un error, una lectura imaginaria, proyectiva o errónea” (p. 300). Schapiro reduce la verdad a la referencia de la proposición -determinación más cercana al utensilio que a la obra; Heidegger invita a ver la verdad en el acontecer de una presencia que reposa en sí misma - lo que emparenta la obra con la pura cosa. Schapiro remite a unos zapatos que supone reales, de modo que lee el cuadro como representación que a su vez indica un sujeto real. Heidegger encuentra en la obra el camino a presenciar el ser del utensilio y el mundo de la campesina. Pero resulta curioso que probablemente Heidegger también se apresura en su conclusión. Al respecto, Derrida afirma: "por un lado, la atribución de Schapiro se mantiene dentro de la estética representativa, e incluso la más empirista [...] Heidegger está más acá de su discurso sobre la verdad en pintura y resulta más ingenuo aún que Schapiro. Su exceso llega hasta el punto de hablar de zapatos de campesino incluso antes de cualquier pregunta "representativa", y ya en el orden de una verdad "presentativa"" (Derrida, 2005, p. 332). ¿Por qué Derrida acusa en este punto de ingenuidad a Heidegger? 
Aunque la puesta en obra de la verdad en el arte sea concebida por Heidegger como presencia, su descripción del mundo de la campesina no deja de ser una que cierra las posibilidades de interpretación en la obra. Probablemente lo que se presenta no sea un "par-de-zapatos" -noción que ya remite a un portador de zapatos-, sino dos zapatos, abiertos, desatados, una presencia cuya verdad yace precisamente en dejar abierta la ausencia.

Así que la pregunta por el desocultamiento de lo ente en la obra podría ser también expresada como ¿qué es lo que se hace presencia en la obra?, ¿qué presencia se abre y se sostiene en la acción que hila una cosa tras otra? Tal vez las palabras de Hincapié ayuden a iluminarla:

Al principio trabajaba con la cama, con escaparates, con mesas, con asientos, con cosas grandes... pero yo no puedo andar con la casa a cuestas, de trasteo en trasteo, entonces empezaron a desaparecer las cosas grandes, quedaron las chiquitas y bueno, fue un proceso de verdad muy fuerte, porque me permitió el dominio de la acción, del tiempo, del rigor y la creatividad. Ese trabajo de experimentar, sí, porque a mí lo que me interesaba era experimentar, a mí no me interesaba crear una obra, sino experimentar con la cotidianidad, con el tiempo, con los espacios, con los objetos, con la sensibilidad, con la quietud, con la televisión, con el comercio, el tacto. (Citada por Gómez, 2010, p. 45)

¿Es posible entender este experimentar en los términos de presencia? ¿Esta acción que experimenta con la tierra y el mundo evidencia el desocultamiento de lo ente? El experimentar de Hincapié no es azaroso ni caprichoso. Por el contrario, está atravesado por el saber hacer con los objetos. Diríase que supone esa techné particular que organiza, que pone límites pero, también, que conoce el trato correcto, la función adecuada, la relación íntima propicia a cada cosa. Según Heidegger, "como saber experimentado de los griegos, la techné es una manera de traer delante lo ente, en la medida en que saca a lo presente como tal fuera del ocultamiento y lo conduce dentro del desocultamiento de su aspecto" (2012, p. 43). Resulta curioso que Hincapié no habla de los objetos como de su propiedad ni testigos de ella misma. En ese sentido, ese experimentar supone haberse desatado de la condición de propietaria, de pertenencia y memoria en los objetos. 
Este saber es el que está implicado en la acción creativa de la artista "como ese dejar que algo emerja convirtiéndose en algo traído delante". El crear de la artista logra dejar que algo emerja a través del trabajo con el rasgo: el experimentar de Hincapié con las cosas y la acción con/sobre las cosas. Ese trabajo consolida o com-pone una figura que hace de la obra una presencia que destaca y permanece en sí misma. En sentido estricto los utensilios de Hincapié dejan de ser útiles, pues si lo fueran su verdad no sería destacable -en lo cotidiano no se puede cuestionar su verdad. Pero en la obra el saber involucrado en el crear demanda a su vez suspender lo útil de los objetos para poder ver el destacar de los mismos en obra, en el acontecer de la obra fuera de lo habitual. La obra destaca y se desplaza de lo habitual por la creación y, con ello, demanda la disposición a seguir su extrañeza y cuidarla -esto es "dejar que la obra sea una obra", que sea "aquello que está presente con carácter de obra" (2012, p. 48). Esto implica que ese experimentar no es solo de la artista, sino que es un crear con el cuidado atento de los que se disponen, o mejor, exponen a la obra. "Al ser-creación de la obra le pertenecen con igual carga esencial los cuidadores que los creadores. Pero es la obra la que, por su esencia, hace posible a los creadores y necesita a los cuidadores" (2012, p. 51). Esto implica que los cuidadores y el artista son llevados a una presencia que puede ponerse en una apertura diferente a lo acostumbrado. Una extrañeza propia del experimentar que arrastra consigo al artista y su público. Heidegger (2012) encuentra en este efecto la esencia poética de la obra:

No es solo la creación de la obra la que es poética, sino también, aunque de otra manera, el cuidado de la obra. En efecto, una obra solo es efectivamente real como obra cuando nos desprendemos de nuestros hábitos y nos adentramos en aquello abierto por la obra para que nuestra propia esencia pueda establecerse en la verdad de lo ente. (p. 54)

De modo que no es extraño que Hincapié se vea abocada a experimentar con los objetos, la cotidianidad, el tiempo, la experiencia misma, y que así desplace lo habitual -y a los cuidadores que la acompañan- a un lugar de extrañeza. Los objetos destacan, pero no son tratados ya como objetos; ella organiza y se mueve, pero con ella se mueve en un ritmo propio cada objeto al punto que su movimiento es el del objeto. 
Las cosas se mueven, y ella es el medio de transporte. Tiempo y movimiento, las cosas en obra empiezan a poetizar: fundan un mundo extraño que se da como presencia, que se funda en una tierra que no deja de ser compartida y que también origina un otro modo de manifestar la verdad de lo así presente para el ser que cuida la obra.

¿Qué podemos decir entonces de la verdad en el arte ahora, o mejor, de la verdad de las cosas en el arte? ¿Llegados a esta presencia podemos aún suponer que ella remite a un sujeto que le corresponde, a una subjetividad que garantizaría la legitimidad de lo presente y para la cual, los objetos son su testigo y memoria? $\mathrm{Si}$ Derrida tiene razón, no solo Schapiro, también Heidegger, se apresuran a enlazar los zapatos del Van Gogh con un sujet del cuadro (un personaje: el sujeto de los zapatos; un tema: el sujeto a quien se ve), de la (re)presentación. Como si dejar los zapatos desatados y a la deriva careciera de valor o sentido (Derrida, 2005, p. 298). Pero los zapatos, tacones, velas, cosas pequeñas y grandes también pueden abrir la presencia del ente. Son entes en sí mismos, pero también son lugares de experiencia y de verdad. Si solo los concebimos por su referencia a un sujeto para el que son utensilios, solo serán medios para llegar a un sujeto. Pero una cosa es una cosa en tanto presencia, y aún si son ornatos -párergon, diría Derrida-, la desnudez resultante de la ausencia del sujeto al que remiten no carece de sentido. Por el contrario, multiplica los sentidos interpretables y dados a la sensación; Derrida (2005) pregunta: “¿Un vestido como suplemento “desnudo" del “desnudo”? ¿Un suplemento sin nada que suplir, que invoca por el contrario lo que suple como su propio suplemento?" (Derrida, 2005, p. 316).

En este juego suplementario se desplaza el enunciado "una cosa es una cosa". Las cosas que son cosas se ubican en un afuera del sujeto, un resto que sin él se mantiene abierto y que, asimismo, se cierra cuando se designa el sujeto: la campesina, Van Gogh, Hincapié. Las cosas que restan al sujeto mantienen su inutilidad y con ello escapan a lo habitual, se instalan en la extrañeza y desafían nuestra presencia y nuestra ausencia en/con ellos y, sin embargo, restan permanentemente abiertos en tanto no requieren cerrar el mundo en un sujeto: "los zapatos siguen estando abiertos al inconsciente del otro. [...] En alquiler, de saldo, en la subasta, al azar, para tomar por donde se pueda, pero sin poseerlos jamás, menos aún guardarlos” (Derrida, 2005, p. 394). 
¿En esta condición se mantiene la necesidad de llamarlos útiles (objetos de uso) para un sujeto, su radical objetivación? Una cosa es todo lo que entra a ser cosa en las relaciones, tiempos y movimientos propios de las cosas que se organizan, se enfilan, se acarician, se trasladan, se muestran y se esconden, ya sean zapatos, artistas o cuidadores. ¿Acaso podría haber visto Hincapié sus cosas sin haber devenido ella misma otra cosa? La verdad y secreto del enunciado "una cosa es una cosa" es que a partir del momento en que se presencia la obra todos los entes, sin importar si son vistos o ven, hacen parte del movimiento y el dictamen que organiza tiempo, espacio, afecto, percepción y cotidianidad.

El juego suplementario es un juego de significantes en el que lo que se muestra como presencia no se cierra en el nombre con el que se clausura la ausencia, sino que la deja abierta a efectos de escritura, de diferimiento. Precisamente lo que en lo cotidiano los utensilios no dejan ver por su subordinación funcional al sujeto, se hace patente en la obra en tanto las cosas remiten entre sí, se enlazan y escriben historias otras que ya no requieren al sujeto, pero que, a la vez, lo desnudan en su materialidad ausente. No es el objeto el complemento del sujeto, sino que es el sujeto el suplemento del objeto, de las cosas. El objeto, significante del significante, tiene en la obra una tarea de escritura en la que los tacones develan al sujeto que somos: son los tacones de la mujer que camina, que se viste, que se cubre, que hace cosas, pero también del cuidador travestido de y por la obra o el soporte femenino de toda masculinidad. Al ver la obra de Hincapié, la verdad de "una cosa es una cosa" es que el sujeto no es la presencia ausente de los objetos, sino el resultado de los juegos de materialidad.

Y ahí las cosas dejan de ser testigos para pasar a ser presencia: nos afectan y revelan lo que somos hoy, aun en aquello que olvidamos que somos: subjetividades en creación, dispuestos y expuestos al mundo de cosas que nos rodea y compone. María Teresa Hincapié no es la única, al menos en el arte contemporáneo colombiano, que se apropia de zapatos. Zapatos como los de Doris Salcedo en Atrabiliarios (1992) -zapatos de mujeres víctimas de la violencia presentados en una sepultura hecha de vejiga de vaca cosida- acusan con aún mayor claridad esta condición, pues probablemente la víctima tras los zapatos no puede ser meramente un cuerpo ajeno de un hecho siniestro concreto, sino cualquiera que es puesto en sus zapatos frente a la obra. 
$\mathrm{O}$, sin duda, las astillas de hueso humano que atraviesan unas botas pantaneras en la obra Emberá-Chamí (2008) de Rosemberg Sandoval -astillas recolectadas de fosas comunes en el país- revelan que es más importante dejar abierta la ausencia que deja la violencia dentro y fuera de la obra para con ello abrir las interrogantes e interpelaciones que cerrar el sentido en un nombre. De lo contario sería caer, según el análisis que Mieke Bal hace de Salcedo, "en la persistente idea kantiana de que el arte está fuera del mundo" (Bal, 2014). Es precisamente la presencia del objeto en tanto tal la que adquiere el potencial de mostrar en las cosas lo que somos. Pero lo particular de la obra de Hincapié es que sin apelar al distintivo contexto histórico de violencia política del país, pone sobre la mesa esta apertura de lo que somos a través de las cosas, de los juegos de sentido en los que nos atrapa el enunciado "una cosa es una cosa". A modo de cierre, y no sin despertar curiosidad, la propia Hincapié poetiza en palabras el ritmo de este mundo de las cosas en su obra:

... traslación aquí. enseguida. en la esquina. en el centro. a un lado. cerquita a él. a ella. muy lejos. más lejos. muchísimo más lejos. lejísimos. aquí las bolsas. aquí el bolso. aquí la tula. aquí la caja. allá las bolsas. aquí la tula y encima el bolso. a un lado la caja. en la esquina el bolso y la tula. en el centro las bolsas de papel y cerquita la caja. vaciamiento. dispersión. todo se vacía. todo sale. todo se dispersa. se riega. se mezcla. se detienen. se cuadran uno tras otro indiferentemente. enmarcan un espacio que se envuelve. se separan por grupos uno al lado del otro. grupos comunes. donde se parecen. porque son blancos. porque son de tela. porque son vestidos. porque son de plástico. porque son largos. porque son cubiertos. porque es loza. porque son frascos. porque se necesitan el uno al otro como la crema y el cepillo. pero también la crema sola y el cepillo con otros cepillos o solo también. todas las flores aquí. los vestidos extendidos. los negros cerca a mí los rosados aquí. los pañuelos solos. la colcha sola. los cubiertos solos. las bolsas solas. los lápices solos. los vestidos solos. los colores solos. la escoba sola. las cebollas solas. las zanahorias solas. el maíz solo. el azúcar solo. la harina sola. el plástico solo. la bolsa sola. la tula sola. la caja sola y vacía. el espejo solo. los zapatos solos. las medias solas. las yerbas solas. yo sola. el solo. nosotros solos. un espacio solo. un rincón solo. una línea sola. una sola media. un solo zapato. todas las cosas están solas. todos estamos solos. un montón de arroz. un montón de azúcar. un montón de sal. un montón de harina. un montón de café. un montón de cosas... (citada por Roca, 2010, p. 163) 


\section{Referencias}

Bal, M. (2014). De lo que no se puede hablar. Medellín, Colombia: Universidad Nacional de Colombia.

Derrida, J. (2005). La verdad en pintura. Buenos Aires, Argentina: Paidós.

Domínguez, J. (1991). La teoría estética en Heidegger. Areté, III(2), 184-205.

Gómez, N. (2010). ¿Acaso es una cosa? En J. Serna, N. Gómez, y F. González, Elemental. Vida y obra de María Teresa Hincapié (pp. 36-68). Bogotá, Colombia: Laguna Libros.

Heidegger, M. (2012). El origen de la obra de arte. En M. Heidegger, Caminos de bosque (pp. 11-62). Madrid, España: Alianza.

Roca, J. I. (2010). Los espacios y las cosas. El mundo interior de María Teresa Hincapié. En J. Serna, N. Gómez, \& F. González, Elemental. Vida y obra de María Teresa Hincapié (pp. 160-163). Bogotá, Colombia: Laguna Libros.

Schapiro, M. (1994). The still life as a personal object -A note on Heidegger and Van Gogh. En M. Schapiro, Theory and philosophy of art: style, artist and society (Selected papers) (pp. 135-142). NY: George Braziller Inc. 